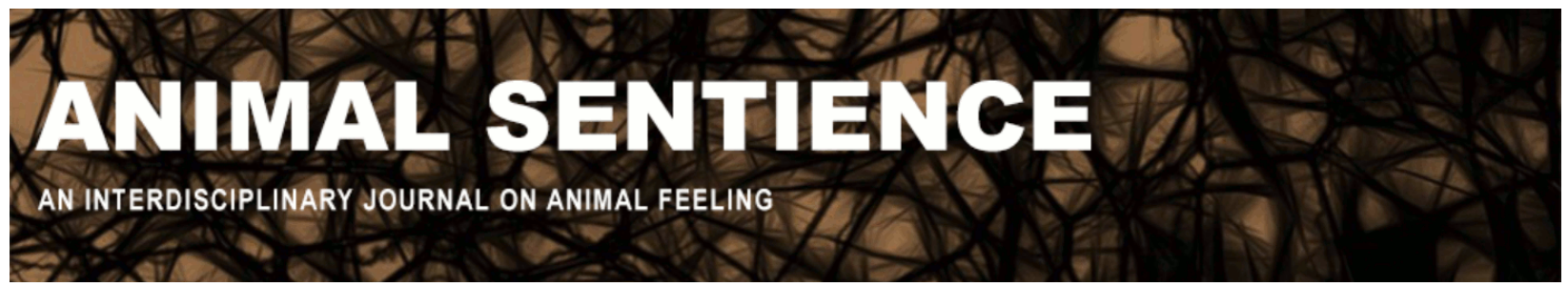

Cecconi, Benedetta; Annen, Jitka; and Laureys, Steven (2020) Can human neurological tests of consciousness be applied to octopus?. Animal Sentience 26(28)

DOI: $10.51291 / 2377-7478.1667$

Date of submission: 2021-01-06

Date of acceptance: 2021-01-08

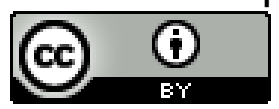

This article has appeared in the journal Animal

Sentience, a peer-reviewed journal on animal

cognition and feeling. It has been made open access,

free for all, by WellBeing International and deposited

in the WBI Studies Repository. For more information,

please contact

wbisr-info@wellbeingintl.org.

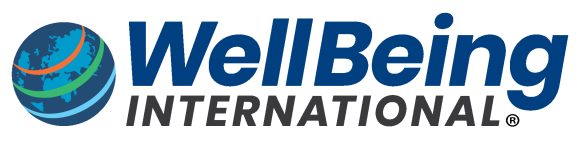

SOLUTIONS FOR PEOPLE, ANIMALS AND ENVIRONMENT 


\title{
Can human neurological tests of consciousness be applied to octopus?
}

Commentary on Mather on Octopus Mind

\author{
Benedetta Cecconi, Jitka Annen, Steven Laureys \\ Coma Science Group, GIGA-Consciousness, University of Liège, Liège, Belgium \\ Centre du Cerveau, University Hospital of Liège, Liège, Belgium
}

\begin{abstract}
If the anatomy, physiology and behaviour of a species differ substantially from our own, as in the case of the octopus, can we infer that the species is unconscious? In the daily clinical care of patients with disorders of consciousness we face many similar challenges: our current approach with these patients - a combination of behavioural and brain imaging-based assessments - might also be a viable route to investigating octopus consciousness.
\end{abstract}

Benedetta Cecconi, doctoral student at the Coma Science Group (GIGA-CONSCIOUSNESS), works on (dis)connected consciousness, combining the perspectives of cognitive neuroscience and philosophy. Website

Jitka Annen, neurobiologist at the Coma Science Group (GIGACONSCIOUSNESS) studies the relationship between brain structure and function at various spatiotemporal scales in a range of topics including consciousness, (dis)connectedness, cosmonauts in zero gravity, and cognition. Website

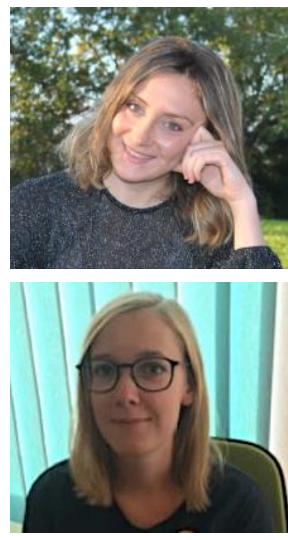

Steven Laureys, Clinical Professor (ULg) and Research Director at the Belgian National Fund of Scientific Research (FNRS), leads the Coma Science Group at the GIGA (ULg) and Department of Neurology, Sart Tilman Liège University Hospital. His main research interest is neurology of consciousness in patients with disorders of consciousness (DOC). Website

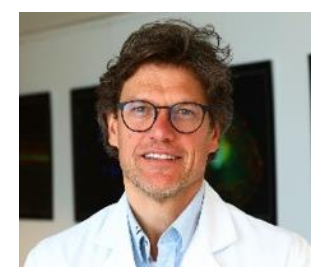

Mather (2019) examines the broad spectrum of behaviours and presumed cognitive abilities of octopuses and wonders whether a mind (i.e., consciousness) can be inferred from some of their capacities. Answering this question calls for operationalizing consciousness in this species: the properties of consciousness need to be identified and the corresponding criteria developed. There is not yet scientific agreement on a definition of consciousness and thus on its properties, let alone criteria. Several criteria have been proposed (e.g., Seth, 2009). All these criteria, however, have been developed anthropocentrically, starting from observations of consciousness in our own species through subjective reports and comparing the resulting data with those recorded in healthy human animals.

In trying to apply these criteria far from the human context in which they were developed, various obstacles arise: for example, if we cannot find a functional equivalent of the thalamocortical system in brain organizations different from our own, how can we 
interpret their structural and functional substrates? More generally, if the anatomy, physiology, and behaviour of a species are substantially different from ours, can we conclude that that species is unconscious (cf. Key, 2016, and accompanying commentary)?

Many of these challenges are similar to those we face every day in the care of patients with disorders of consciousness (DOC) after severe brain damage. The relatives of these patients usually come to our clinic to learn about the state of consciousness of their loved ones. The diagnosis and prognosis we provide has major repercussions, as it determines treatment choices, pain management and potential end-of-life decisions. Knowing the level of consciousness of patients -- or of any sentient organism -- shapes our behaviour toward them. We are ethically called upon to test and evaluate humans' state of consciousness -and ethical questions also arise with the octopus.

Currently, in our daily practice with DOC patients, we use a combination of diagnostic approaches, bottom-up (behaviour-based assessment) and top-down (brain imaging-based assessment). We examine diverse cognitive and noncognitive behaviours and residual brain activity, combining a variety of analyses and methods (Gosseries et al. 2014). Although this approach provides us with insight into the potential experiences and capabilities of DOC patients, we still lack a baseline against which to evaluate these patients' data, particularly for the top-down approach. For example, in interpreting brain imaging data in patients we use the healthy population as the standard. Yet, the brain of DOC patients may reorganise after injury through brain plasticity (Mogensen, 2011). This altered reorganization may mean that there is no longer direct standard against which patient data can be compared.

The same applies to the octopus and its decentralised nervous system which, despite its organisation being so different from that of other animals, nevertheless seems suitable for supporting remarkable cognitive capacities. These considerations invite us to consider the possibility that consciousness comes not only in different quantities but also in different "qualities": as Godfrey-Smith (2016) points out, evolution may "build minds twice over". That is, one and the same function (consciousness) may take different forms, depending on different environmental and social pressures.

The combination of top-down and bottom-up assessment that we currently use with DOC patients may also be relevant to investigating the octopus mind. Although applying brain imaging methods to octopuses is unquestionably difficult, some researchers have already begun to take up the challenge (Jiang, 2015). If we could implement reliable brain imaging in octopuses, some of the paradigms we currently use with DOC patients could be tested in this cephalopod species. For example, if we could carry out consistent ERP studies (Annen et al. 2020)in octopuses, we could monitor their responses to a test we use daily with our patients to diagnose their level of consciousness: the local/global auditory evoked potential paradigm (Bekinschtein, 2009). In this "oddball" paradigm, two levels of regularities are established, one at a local (within-trial) level and one at a global (across-trial) level. It is assumed that specific EEG responses to disruptions of global regularities require active maintenance of perceptual representations over time, indicating conscious processing, whereas responses to disruptions of local regularities indicate automatic (unconscious) processing. To determine 
whether an octopus could detect a global irregularity would draw us into its cognition or perhaps its consciousness ${ }^{1}$.

Such top-down measures, integrated with other behavioural tests -- carefully designed to test complex cognition and not cognitive shortcuts, as Schnell \& Vallortigara (2019) point out - may help guide our interactions with nonverbal organisms and reduce uncertainties about their (potential) cognition. In view of the current uncertainties regarding behavioural and neurophysiological correlates of consciousness, we should remain cautious in our inferences. Answering the question "What is it like to be an octopus?", or "what is it like to be a DOC patient?" may require not just an inference but an "imaginative leap" (Godfrey-Smith, 2019).

\section{References}

Annen, J., Laureys, S., \& Gosseries, O. (2020). Brain-computer interfaces for consciousness assessment and communication in severely brain-injured patients. In Handbook of Clinical Neurology (Vol. 168, pp. 137-152). Elsevier.

Bekinschtein, TA., Dehaene, S., Rohaut, B., Tadel, F., Cohen, L., Naccache, L. (2009) Neural signature of the conscious processing of auditory regularities. Proceedings of the National Academy of Sciences (PNAS). 3;106(5): 1672-7.

Godfrey-Smith, P. (2016) Other Minds: The Octopus, the Sea, and the Deep Origins of Consciousness. William Collins.

Godfrey-Smith, P. (2019) Octopus experience. Animal Sentience 26(18)

Gosseries, O., Di, H., Laureys, S., Boly, M. (2014) Measuring consciousness in severely damaged brains. Annual Review of Neuroscience. 37: 457-78.

Jiang, X., Lu, H., Shigeno, S., Tan, LH., Yang, Y., Ragsdale, CW., Gao, JH. (2014) Octopus visual system: a functional MRI model for detecting neuronal electric currents without a blood-oxygen-level-dependent confound. Magnetic Resonance in Medicine. 72(5): 1311-9.

Key, Brian (2016) Why fish do not feel pain. Animal Sentience 3(1)

Mather, J. (2019) What is in an octopus's mind? Animal Sentience 26(1).

Mogensen, J. (2011) Reorganization of the injured brain: implications for studies of the neural substrate of cognition. Frontiers in Psychology. 2:7.

Schnell, A. and Vallortigara, G. (2019) 'Mind' is an ill-defined concept: Considerations for future cephalopod research. Animal Sentience 26(16).

Seth, Anil (2009) Explanatory Correlates of Consciousness: Theoretical and Computational Challenges. Cognitive Computation. 1: 50-63.

\footnotetext{
${ }^{1}$ Although the link between active information maintenance and consciousness is still debated.
} 